\title{
Windmills and Pill Mills: Can PDMPs Tilt the Prescription Drug Epidemic?
}

\author{
Hallam Gugelmann • Jeanmarie Perrone • Lewis Nelson
}

Published online: 21 November 2012

(C) American College of Medical Toxicology 2012

\begin{abstract}
Prescription drug monitoring programs (PDMPs) are state-based registries of prescriptions for specific controlled substances. This overview will describe the history and funding of these databases, address those characteristics thought to be of greatest utility for PDMPs and review current literature regarding PDMP effectiveness and their potential limitations. Although more extensive research on PDMP outcomes is needed, these databases are an essential component in ongoing efforts to establish safe and compassionate prescription opioid stewardship.
\end{abstract}

Keywords Chronic pain · Drug therapy · Drug monitoring · Drug and narcotic control/legislation · Prescription drugs

\section{Introduction}

Prescription drug monitoring programs (PDMPs) are state-administered databases that collect, store, and dis-

H. Gugelmann $(\bowtie)$

Department of Emergency Medicine, Perelman School of

Medicine, University of Pennsylvania,

Ground Ravdin 3400 Spruce Street,

Philadelphia, PA 19104, USA

e-mail: hallamg@gmail.com

\section{J. Perrone}

Division of Medical Toxicology, Department of Emergency

Medicine, Perelman School of Medicine, University of

Pennsylvania,

Ground Ravdin, 3400 Spruce Street,

Philadelphia, PA 19104, USA

\section{Nelson}

Fellowship in Medical Toxicology, Department of Emergency

Medicine, New York University School of Medicine,

455 First Avenue,

New York, NY 10016, USA tribute data on controlled substance prescribing. Authorized users-including prescribers, pharmacists, and/or law enforcement, depending on individual state lawsaccess these databases in order to track and change prescribing patterns. Although there is significant variability in administrative aspects of PDMPs among states, their purpose is to support legitimate medical use of controlled substances while limiting drug misuse, abuse, and diversion [1]. These databases have been used to identify and curb individual use of multiple providers (doctor shopping) and to facilitate law enforcement investigations. PDMPs can potentially be a resource for tracking the impact of public health interventions aimed at prescribing and consumption patterns.

As of June 2012, all states (with the exception of Missouri as well as the District of Columbia) have enacted legislation creating PDMPs, although only 40 states currently report having operational PDMPs [2]. While progress in expanding and improving these programs has proceeded rapidly over the past 5 years, variability between programs and the lack of information sharing between states significantly limit their utility to both clinicians and law enforcement personnel. This article discusses the history of PDMPs, reviews their individual characteristics, and addresses their potential effectiveness in curbing prescription opioid abuse.

\section{Definitions}

Terms used in this review are defined as follows:

Controlled substances are drugs or chemicals under governmental regulation; in the USA, this includes all substances in Schedules I-V as defined in the Controlled Substances Act of 1970 (Box 1). 


\begin{tabular}{|c|c|c|}
\hline \multicolumn{3}{|c|}{$\begin{array}{l}\text { The Controlled Substances Act (21 U.S.C. } \$ 801 \text { et seq.) establishes Schedules for } \\
\text { controlled substances (including drugs), ranging from Schedule I (most restrictive) to } \\
\text { Schedule V (least restrictive). Drugs on Schedule I have no currently accepted medical } \\
\text { use in the United States and are not available by prescription. Drugs with recognized } \\
\text { medical uses are on Schedules II through V, with each successive Schedule representing } \\
\text { a lower risk of abuse. }\end{array}$} \\
\hline Schedule I & & heroin, marijuana \\
\hline Schedule II & - & oxycodone, hydromorphone \\
\hline Schedule III & - & buprenorphine, hydrocodone/codeine compounds \\
\hline Schedule IV & - & benzodiazepines, barbiturates \\
\hline Schedule V & - & low-dose codeine products, pregabalin \\
\hline $\begin{array}{l}\text { CRS Report I } \\
\text { Substances, b } \\
\text { httn //www f }\end{array}$ & & $\begin{array}{l}\text { Legal Issues Relating to the Disposal of Dispensed Controlled } \\
\text { T. Yeh. Accessed August 18, } 2012 \text { from } \\
\text { p/crs/misc/R40548.pdf }\end{array}$ \\
\hline
\end{tabular}

Prescribers include those practitioners authorized to write legal prescriptions for controlled substances. Prescribers include physicians, nurse practitioners, dentists, and certain other healthcare professionals.

Drug diversion involves the removal of drugs from legal marketplaces and distributing them in illegal ones, which includes distribution to friends or family. Sale, theft, and forgery of either prescriptions or Drug Enforcement Agency (DEA) numbers are known components of drug diversion [3].

Doctor shopping involves a single individual receiving prescriptions for the same or related medication independently from multiple providers [4].

The misuse of prescription substances entails use inconsistent with the intent of the original prescription [5]. For example, taking extra doses of a therapeutic medication for worsening pain is misuse, as is use of a medication that is prescribed for another person.

Abuse is a maladaptive pattern of substance use leading to clinically significant impairment or distress, as manifested by impaired ability to fill obligations, substance use in physically hazardous environments, recurrent associated legal problems, and continued substance abuse despite resulting social or interpersonal problems [6].

\section{History and Funding}

The need for creating and maintaining a closed system of distributors of potentially addictive harmful drugs was first acknowledged with the Harrison Narcotics Act of 1914. The provisions of this piece of legislation were further solidified with the Controlled Substances Act of 1970, which required DEA registration and the maintenance of records, while formally endorsing the first type of PDMP: triplicate or "three-part order" forms [7].

Despite these initial efforts, only 10 states had true PDMPs by 1992 [8]. The cost of PDMP implementation has been a significant barrier to broad expansion and implementation. The Congressional Research Service reported in July 2012 that PDMP startup costs range from $\$ 450,000$ to more than $\$ 1.5$ million, with annual operating costs from $\$ 125,000$ to nearly $\$ 1.0$ million [9]. The US Government Accountability Office (GAO) has identified several major factors contributing to a PDMP's operational costs (Box 2). 


\section{Box 2. Major factors contributing to the cost of state prescription drug monitoring programs. \\ 1. Size of the state \\ 2. Differences in implementation
a. Number of Schedules monitored or drugs covered, optional monitoring of non-scheduled drugs
b. Data collection methods
c. Proactive vs. reactive data use
d. Data housing entity
e. Data analysis methods

3. Number of pharmacies reporting prescription information to the PDMP

4. Number of providers and law enforcement agencies requesting prescription information

5. Number of staff required to ensure smooth operation of the PDMP

6. Number and type of outside contractors required to run the PDMP

As summarized by Blumenschein et al. ${ }^{8}$ Original data from 2002 Government Accountability Office (GAO) Report to the Subcommittee on Oversight and Investigations, Committee on Energy and Commerce, House of Representatives. $^{10}$

Initially, states financed PDMPs almost exclusively using state general funds, state grants, and a variety of fees (including prescriber and pharmacy licensing, state controlled substance registration, and fees from health insurers) [10]. Increased efforts toward the creation, standardization, and funding of PDMPs came with the creation of the National Alliance for Model State Drug Laws (NAMSDL), a 501(c)(3) nonprofit organization started by the 1992 bipartisan President's Commission on Model State Drug Laws and charged by Congress with creating a representative, optimal code of laws addressing drug abuse [11]. According to its website, the NAMSDL currently focuses on answering states' "legislative and policy questions" related to PDMPs, while also providing a set of guidelines for the creation of a "strong" PDMP (see below) [1].

However, NAMSDL was not funded by Congress until 1995, and significant funds for the creation of PDMPs were not appropriated until the creation of two federal programs years later. In 2002, Congress created the Harold Rogers Prescription Drug Monitoring Program (HRPDMP), funded through the US Department of Justice. HRPDMP provides planning, implementation, and enhancement grants for state PDMPs, with an emphasis on interstate information sharing through the Prescription Monitoring Information Exchange (PMIX) [12]. In 2005, President George W. Bush signed the National All Schedules Prescription Electronic Reporting Act (NASPER), which authorizes the US Department of Health and Human Services to award grants for states to create PDMPs or enhance existing programs. In particular, this law focuses on the use of PDMPs for the early identification of addiction. NASPER also includes provisions for the creation of a set of best practices in the establishment of a new PDMP, and requires ongoing assessment of potential negative impacts, including decreased patient access to treatment, changes in pediatric patient treatment, and decreased research or clinical trial enrollment [13, 14]. Federal appropriations to these programs have varied significantly from year to year; while HRPDMP has disbursed from \$2 to 10 million per year, NASPER has only received funding in 2009 and 2010 [9]. 


\section{Individual PDMP Characteristics by State}

Recommended components of a "strong" PDMP have been established by NAMSDL (Box 3). A recent publication expands on these recommendations to include: ease of access, standardization of content, real-time updates, mandatory pharmacy reporting, inclusion of all DEA Schedules II-V and "drugs of concern", and additional, strictly monitored access for nonprescribers [15]. Despite the existence of these guidelines, significant variability exists between PDMP characteristics from state to state. This variability includes:

Number of Schedules Included. While Pennsylvania records Schedule II drugs only, most other states have expanded their databases to track Schedules II-IV or even II-V. The expansion of a PDMP to include additional Schedules may prevent an increase in prescribing of those drugs not included in the registry. For example, prescriptions for nonbenzodiazepine sedatives increased significantly in New York in 1989 after benzodiazepines were added to that state's triplicate prescription PDMP [9]. In addition, several states include provisions for the inclusion of nonscheduled medications in PDMPs. This may facilitate surveillance of new medications of concern, which is particularly important since formal scheduling of substances can take 6 months or more [16].

Required Frequency of Updates. With the advent of internet-based databases, the ability to record prescriptions at the precise time of dispensing has improved significantly. At the same time, some states continue to require only intermittent updates, with some states requiring updates as infrequently as 14-day intervals. From a clinical perspective, the inability to access upto-date information at the time of prescribing significantly impairs the utility of a PDMP [15]. Essential to these efforts has been the use of computer- and internetbased programs, which greatly facilitate rapid centralized storage and access of PDMP data.

Housing Entities. State PDMPs are most commonly operated by state boards of pharmacy. Other housing entities include state Health Departments, law enforcement agencies, non-pharmacy licensing boards, and consumer protection agencies. The impact of the entity under which a PDMP is housed is unclear, but may affect Health Insurance Portability and Accountability Act (HIPAA) protections afforded, public health surveillance utility, law enforcement functionality, and clinical applicability.

Accessibility. Individual states strictly govern who is allowed to access their PDMP data. Only one state (PA) allows law enforcement agencies exclusive access to PDMP data, and excludes access by all other entities. Other states allow closely regulated access by prescribers, pharmacists, medical examiners, and law enforcement personnel. A prescriber's ability to access PDMP data at the time of prescribing may significantly affect a PDMP's impact on prescribing practices [17, 18].

Access Requirements. Several state PDMP laws explicitly state that individual prescribers are not required to access a PDMP prior to prescribing controlled substances. This provision ensures that prescribers are exempt from civil liability on the basis of its use [8]. Alternatively, Nevada mandates that prescribers review database information prior to prescribing in certain circumstances, including suspicion of drug-seeking behavior, patients new to the practitioner, and patients who have not received a prescription for a controlled substance from the practitioner in the preceding 12 months [19].

Reactive and Proactive Reporting. "Reactive" PDMPs generate individual reports only in response to an inquiry, e.g., providing reports at the time of a single clinical encounter, or on the basis of a law enforcement investigation of an individual. Other PDMPs are "proactive," and actively monitoring prescribing and prescription filling patterns. Under appropriate circumstances, these programs generate unsolicited reports that are sent to the relevant prescribers. The threshold for activation of an unsolicited report also varies from state to state; for example, New York generates an automatic report if an individual has filled prescriptions for Scheduled substances at two or more pharmacies within the previous month [20]. PDMP reports may be sent to prescribers, pharmacies, law enforcement, or other entities, depending on state law. In the clinical setting, the utility of these reports depends on the setting of patient interaction. In cases of isolated prescriber-patient interactions - including emergency departments - proactive reporting is unlikely to be particularly useful.

Prescriber Education. The implementation of a PDMP alone - even with perfect reporting by pharmacies - cannot guarantee awareness and use of these databases. A survey of palliative care physicians in Ohio 5 years after the implementation of that state's PDMP found that while $84 \%$ of respondents knew of the system, less than $59 \%$ of those aware of the program had used it clinically [21]. Regardless of specialty, this survey highlights that without appropriate educational campaigns to encourage their use, PDMPs are unlikely to have a significant effect on prescribing practices or prescription opioid abuse. Even appropriate education may not suffice to ensure adequate levels of PDMP use, and additional incentives for database use may be needed. An additional consideration is that if inappropriate prescribing is not affected through prescriber education, states may follow Nevada's example and require prescriber access (see above), a mandate with the potential to hinder care and with an unclear impact on prescribing practices. 
Interstate Data Sharing. The ability to share PDMP data between states has been a federal goal since 2002. As of July 2012, there are no national standards for state PDMP information sharing, although several states have arranged to implement such programs (Fig. 1). Several states now share PDMP data through the PMIX, outline by the HRPDMP in 2002 [22], and the National Association of Boards of Pharmacy created its own information sharing entity called InterConnect in 2011 [23]. Several acts currently pending Congressional legislation may facilitate the creation of national data registries, including the Food and Drug Administration Safety and Innovation Act (Section 1141, S. 3187), the Medicare and Medicaid FAST Act (H.R. 3399, S. 1251), and the Interstate Drug Monitoring Efficiency and Data Sharing (ID MEDS) Act (H.R. 4292, S. 2254) [9, 24].

Box 3. Components of a Strong Prescription Drug Monitoring Program - National Alliance for Model State Drug Laws. ${ }^{36}$

1. Drugs Monitored

- Federal controlled substances

- Additional controlled substances regulated the state (several states have more extensive controlled substance than federal law specifies) ${ }^{37}$

- Rapid addition of non-controlled substances with high abuse potential (e.g., new drugs)

2. Unsolicited and Proactive Disclosure

- Proactive provision of data on suspicious patterns of both prescriber and recipient behavior to prescribers, dispensers, law enforcement and occupational licensing individuals

3. Disclosure of De-Identified Information

- De-identified data disclosure to researchers for public policy and research purposes

4. Authorized Users

- Including prescribers, dispenses, law enforcement, prosecutorial officials, health licensing agencies or boards for prescribers and dispensers, patients, medical examiners, county coroners and designated representatives of drug and alcohol addiction treatment programs

5. Education, Training or Instruction for Authorized Users

- Education on both appropriate use of the system and on proper prescribing practices

6. Standards and Procedures for Access to and Use of PMP

- Rules and policies for use of PDMPs specifically as an "information tool which can help health professionals intervene with patients who may be abusing or addicted to substances monitored"

7. Linkage to Addiction Treatment Professionals

- Both for prescribers and for patients

8. Interstate Sharing of PMP Data

9. Confidentiality Protections

10. Evaluation Component

- Used to identify cost benefits of the PMP, impacts of the use of PMP data on the practices of authorized users, any recommended operational improvements and other information relevant to policy, research and education involving controlled substances 


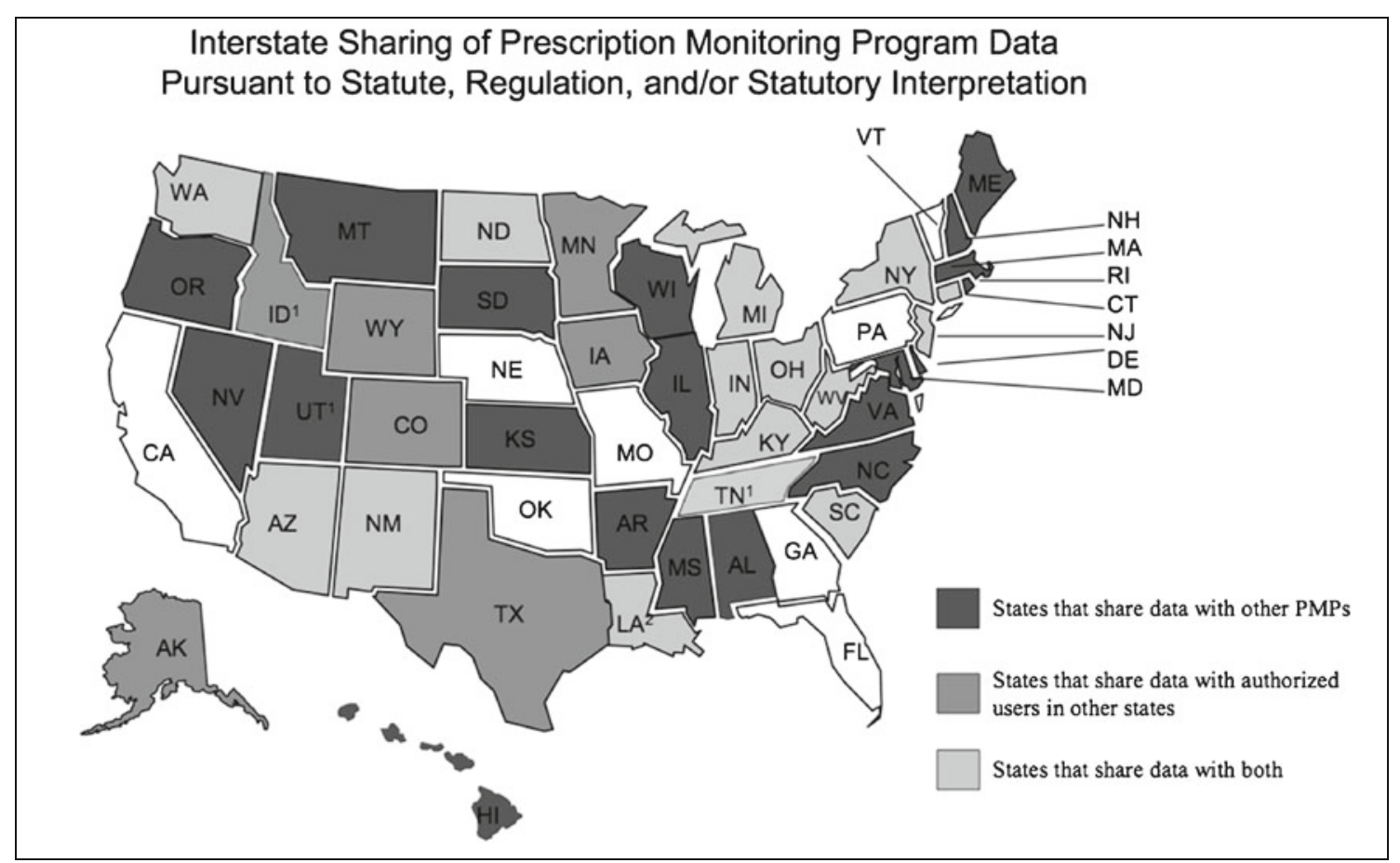

Fig. 1 Interstate Sharing of Prescription Monitoring Program Data, July 2012. Source: National Alliance for Model State Drug Laws [38]. Federally-funded image freely available for reproduction at http://www.namsdl.org/documents/InterstateSharingofPMPData07312012.pdf

\section{Effectiveness of PDMPs}

The theoretical benefits of PDMPs are well cataloged but poorly studied. These include supporting patient access to legitimately prescribed and used controlled substances, identification and prevention of drug abuse and diversion, identification of dependence and addiction patterns to facilitate detoxification treatment referrals, public health surveillance, and for the education of both patients and prescribers about unsafe prescribing patterns [25]. Recent publications also illustrate the possibility that prescribers using a PDMP may detect medication errors, i.e., patients at risk for adverse effects from legitimate prescriptions prescribed by multiple sources [15].

Although data regarding the overall effects of PDMPs is limited, current evidence appears to indicate benefits for both law enforcement and health care. In 2006, the US Department of Justice sponsored an independent evaluation of PDMPs, which tracked Schedule II medication supply and abuse using statistical modeling and two databases: the Automation of Reports and Consolidated Orders System (ARCOS) and the Treatment Episode Data Set [20]. The report found that PDMPs reduce the per capita supply of prescription opioids and thus reduce the probability for abuse, a finding that the study's authors confirmed with a model estimating individual-level response. This study also placed an emphasis on the proactive monitoring and regulation of prescription practices by PDMPs, using statistical modeling to illustrate that the practice of actively contacting prescribers on the basis of PDMP database analyses would indirectly decrease the probability of abuse by decreasing prescribing. Extrapolation of this study's findings to current databases is somewhat restricted by its authors' inclusion of Schedule II substances only.

Using ARCOS and National Center for Health Statistics data from 1999 to 2005, however, a 2011 study found no difference in the incidence of opioid overdose mortality between states with and without PDMPs, and concluded that PDMPs would need to be modified in order to have a significant effect on mortality [26]. Importantly, the rapid improvement in PDMP operability limits the use of data from a decade earlier.

Since the release of these reports, a report published by the GAO in 2012 specifically addressed the utility of PDMPs for law enforcement. Using data from Kentucky, Nevada, and Utah, this study concluded that PDMPs can significantly decrease the time and effort required by law enforcement in researching drug diversion cases [27].

A 2012 assessment of PDMP impact utilized the RADARS ${ }^{\circledR}$ (Researched, Abuse, Diversion and AddictionRelated Surveillance) poison center and opioid treatment surveillance databases from 2003 to 2009 and found that states without a PDMP had significant increases in opioidrelated incidents reported to poison control centers. Quarterly changes in states without PDMPs included a $1.9 \%$ increase in intentional opioid exposures and a $4.9 \%$ 
increase in opioid treatment admissions; these numbers were 0.2 and $2.6 \%$, respectively, for states with PDMPs [28].

Additional studies have found significant benefits of PDMPs for practitioners. A study of emergency medicine clinicians conducted in Ohio in 2010 found that prescribing practices changed in $41 \%$ of encounters when PDMP data was provided prior to prescribing. Study authors also reported that, in some cases, PDMP data resulted in increased rather than decreased prescribing, indicating the possibility that a PDMP could facilitate more individualized pain medication prescribing. This single-institution study was somewhat limited by the fact that one study author treated approximately one third of the patients studied [17]. In 2008, a study of buprenorphine use in France for long-term opioid maintenance found that implementation of a PDMP correlated with a precipitous drop in doctor-shopping, as measured by a variable combining early refills and multiple prescribing practitioners per patient. This study was a retrospective, environmental analysis, however, and did not account for other events (educational campaigns, downward economic trends) that may have affected prescribing practices [29]. Despite these studies' respective limitations, they both illustrate the significant potential benefits of PDMP implementation.

\section{Potential Unintended Consequences of PDMPs}

Several critical assessments of PDMPs have noted possible unintended consequences of increased PDMP implementation and utilization [30]. Potential effects of PDMPs include a decrease in legitimate prescribing of controlled substances due to the increased scrutiny perceived by prescribers. The result of this Hawthorne-like effect could include not only inadequate treatment of pain, but also the increased prescribing of inappropriate or inadequate alternate medications, as was noted in New York when benzodiazepines were added to that state's paper-based prescription monitoring registry in 1989 [9]. Although there is concern that the significance of this "shift" in prescribing seen with New York's triplicate prescription program may have been overemphasized [31], medication substitution by prescribers remains a potential unintended effect of broad-spread PDMP implementation and use. At this time, there is no evidence that PDMPs result in oligoanalgesia.

Patient-related concerns are also prevalent in discussions regarding PDMPs. One predominant concern deals with patient privacy, including concerns regarding unfettered law enforcement access to prescription information. Although most state laws regarding PDMPs have specific clauses addressing when and how law enforcement may access the database, concerns surrounding privacy and security of individual information persist, along with the theory that patients may be less inclined to fill legitimate prescriptions for controlled substances if they fear scrutiny. Although concerns related to HIPAA have also surfaced, several clauses within this act are specifically relevant to PDMPs. These include several sections of HIPAA's Privacy Rule, which allows for disclosure of personal health information in the case of public health, health oversight activities, and law enforcement [32].

Optimally, identification of potential aberrant use by a patient should allow a clear series of responses that include counseling the patient and referral for substance abuse treatment as appropriate. However, limitation in both time and education on proper counseling techniques may alienate patients without having the intended consequence of changing their opioid use patterns. In addition, the paucity of referral sources for addiction services remains a concern.

The public health impact of the potential, relatively abrupt reduction in the supply of prescription opioids in particular is a source of concern. As states increasingly implement and enforce individual components of their PDMPs, illegal prescription drug activity may increase in neighboring states without PDMPs. Similarly, there exists significant concern that prescription opioid abusers will simply obtain drugs from neighboring states in the event of increased enforcement. Perhaps the most significant possible result of the implementation of PDMPs, however, is that reducing the supply of prescription opioids may result in users switching to other substances, in particular heroin, a fear outlined by a 2007 threat assessment from the National Drug Intelligence Center of the US Department of Justice [33]. Efforts at curbing prescription opioid abuse have yet to be successful enough to bring about a discernible change in heroin and other illicit, nonprescription high-risk drug use.

As efforts toward PDMP implementation and standardization continue, several other possible outcomes remain to be studied and addressed. The amount of time required to access and verify prescription information in a PDMP could adversely affect patient care, especially when viewed cumulatively in the setting of a busy outpatient clinic or an emergency department. While the act of presenting a patient with their opioid prescription records can delay the care of other patients, it may also become a source of distrust between patient and provider. In addition, pain control has long been linked to patient satisfaction, and prescribers may minimize their use of a PDMP if they fear that satisfaction ratings may be adversely affected. Although efforts geared at increasing prescriber utilization of PDMPs continue, there is no evidence at this time that adopting their use will guarantee long-term compliance by practitioners. It is conceivable that providers may fear the inappropriate restriction of legitimate prescribing at the hands of regulators and law enforcement officials.

Despite these misgivings, several prescribers' governing bodies-including the American College of Emergency Physicians-have recognized the potential utility of PDMPs, and have endorsed clinical use of these databases at time of prescribing [34]. 


\section{Summary}

Although more research on the immediate and downstream effects of PDMPs is needed, these databases show significant promise in stemming the tide of prescription opioid diversion, abuse, dependence, and overdose. If states heed current recommendations regarding design, implementation, maintenance, security protections, and user education, PDMPs could prove to be an essential component in curtailing the current epidemic of prescription opioid abuse.

\section{Conflict of Interests None}

\section{References}

1. National Alliance for Model State Drug Laws. http://www. namsdl.org/presdrug.htm. Accessed on: 16 Jul 2012

2. The Alliance of States with Prescription Monitoring Programs (2012) Status of prescription monitoring programs. http:// www.pmpalliance.org/pdf/pmpstatustable2012.pdf. Accessed on: 16 Jul 2012

3. Inciardi JA, Surratt HL, Kurtz SP, Cicero TJ (2007) Mechanisms of prescription drug diversion among drug-involved club- and street-based populations. Pain Med 8(2):171-183

4. Wang J, Christo PJ (2009) The influence of prescription monitoring programs on chronic pain management. Pain Physician 12:507-515

5. White AG, Birnbaum HG, Schiller M, Tang J, Katz NP (2009) Analytic models to identify patients at risk for prescription opioid abuse. Am J Manag Care 15(12):897-906

6. American Psychiatric Association (1994) Diagnostic and statistical manual of mental disorders, fourth edition. American Psychiatric Press: Washington, DC

7. Cooper JR et al (1993) Impact of prescription drug diversion control systems on medical practice and patient care. NIDA research monograph 131. U.S. Department of Health and Human Services, National Institute on Drug Abuse, Rockville

8. Blumenschein K, Fink JL, Freeman PR, James K, Kirsh KL, Steinke DT, Talbert J (2010) Review of prescription drug monitoring programs in the United States-Kentucky All Schedule Prescription Electronic Reporting Program (KASPER) Evaluation Team. Institute for Pharmaceutical Outcomes and Policy Department of Pharmacy Practice and Science. http://chfs.ky.gov/NR/ rdonlyres/85989824-1030-4AA6-91E1-7F9E3EF68827/0/ KASPEREvaluationPDMPStatusFinalReport6242010.pdf. Accessed on: 16 Jul 2012

9. Finklea KM, Bagalman E, Sacco LN (2012) Prescription drug monitoring programs. Congressional Research Service, July 10th, 2012. http://www.fas.org/sgp/crs/misc/R42593.pdf. Accessed on: 26 Jul 2012

10. U.S. General Accounting Office (2002) Prescription drugs: state monitoring programs provide useful tool to reduce diversion, GAO-02-634, May 2002, p 3. http://www.gao.gov/assets/240/ 234687.pdf. Accessed on: 26 July 2012

11. National Alliance for Model State Drug Laws Website. http:// www.namsdl.org/about.htm. Accessed on: 16 Jul 2012

12. U.S. Department of Justice, Office of Justice Programs, Bureau of Justice Assistance website. https://www.bja.gov/ProgramDetail s.aspx?Program_ID=72. Accessed on: 5 Aug 2012
13. US Department of Justice Drug Enforcement Administration (2010) State prescription drug monitoring programs. http:// www.deadiversion.usdoj.gov/faq/rx_monitor.htm. Accessed on: 16 Jul 2012

14. US Department of Health and Human Services (2005) National All Schedules Prescription Electronic Reporting Act of 2005: a review of implementation of existing state controlled substance monitoring programs. Center for Substance Abuse Treatment, Substance Abuse and Mental Health Services Administration. http:// www.dpt.samhsa.gov/doc/NASPER\%2009142007.doc. Accessed on: 5 Aug 2012

15. Perrone JP, Nelson LS (2012) Medication reconciliation for controlled substances: an "Ideal" prescription-drug monitoring program. N Engl J Med 366(25):2341-2343

16. National Alliance for Model State Drug Laws. http://www.namsdl.org/ documents/StrongComponentsPMPStatuteProgram6-2012.pdf. Accessed on: 26 Jul 2012

17. Baehren DF, Marco CA, Droz DE, Sinha S, Callan EM, Akpunonu P (2010) A statewide prescription monitoring program affects emergency department prescribing behaviors. Ann Emerg Med 56(1):19-23. doi:10.1016/j.annemergmed.2009.12.011, e1-3

18. Gugelmann HM, Perrone J (2011) Can prescription drug monitoring programs help limit opioid abuse? JAMA 306(20):2258-2259. doi:10.1001/jama.2011.1712

19. Nevada Revised Statue. NRS 639\$23507. http://www.leg.state. nv.us/nrs/NRS-639.html\#NRS639Sec23507. Accessed on: 5 Aug 2012

20. Simeone R, Holland L (2006) An evaluation of prescription drug monitoring programs, vol 12210. US Dept of Justice, Office of Justice Programs, Washington, DC

21. Feldman L, Williams KS, Coates J, Knox M (2011) Awareness and utilization of a prescription monitoring program among physicians. J Pain Palliat Care Pharmacother 25(4):313-317. doi:10.3109/ 15360288.2011.606292

22. National Alliance for Model State Drug Laws, Prescription Monitoring Information Exchange (PMIX). http://www.pmpalliance.org/ content/prescription-monitoring-information-exchange-pmix. Accessed on: 5 Aug 2012

23. National Association of Boards of Pharmacy-Prescription Monitoring Program (PMP) InterConnect Fact Sheets. www.nabp.net/ programs/pmp-interconnect/nabp-pmp-interconnect/ and http:// www.nabp.net/programs/assets/PMPInterconnectFactSheet.pdf. Accessed on: 5 Aug 2012

24. Interstate Drug Monitoring Efficiency and Data Sharing Act of 2012. The Alliance Monitor, Mar-Apr 2012. http:// www.pmpalliance.org/content/interstate-drug-monitoringefficiency-and-data-sharing-act-2012

25. S. 2254: ID MEDS Act status reported by www.govtrack.us at http://www.govtrack.us/congress/bills/112/s2254. Accessed on: 5 Aug 2012

26. National Alliance for Model State Drug Laws, Prescription Drug Monitoring Programs: a brief overview. http://www.namsdl.org/ documents/PMPsBriefOverview8-17-2010.pdf. Accessed on: 17 Aug 2010

27. Paulozzi LJ, Kilbourne EM, Desai HA (2011) Prescription drug monitoring programs and death rates from drug overdose. Pain Med 12(5):747-754. doi:10.1111/j.1526-4637.2011.01062.x

28. United States Government Accountability Office (2002) Prescription drugs: state monitoring programs provide useful tool to reduce diversion. http://www.gao.gov/new.items/d02634.pdf. Accessed on: 26 Jul 2012

29. Reifler LM, Droz D, Bailey JE, Schnoll SH, Fant R, Dart RC, Bucher Bartelson B (2012) Do prescription monitoring programs impact state trends in opioid abuse/misuse? Pain Med 13(3):434 442. doi:10.1111/j.1526-4637.2012.01327.x 
30. Pradel V, Frauger E, Thirion X, Ronfle E, Lapierre V, Masut A, Coudert C, Blin O, Micallef J (2009) Impact of a prescription monitoring program on doctor-shopping for high dosage buprenorphine. Pharmacoepidemiol Drug Saf 18(1):36-43

31. Fishman SM, Papazian JS, Gonzalez S, Riches PS, Gilson A (2004) Regulating opioid prescribing through prescription monitoring programs: balancing drug diversion and treatment of pain. Pain Med 5(3):309-324

32. Wolfe SM, Lurie P (1992) Regulation of benzodiazepine prescription. JAMA 268(4):472, author reply 474

33. Health Insurance Portability and Accountability Act (HIPAA) Privacy Rule and Prescription Drug Monitoring Programs (PMPs). http://www.namsdl.org/documents/HIPAAandPMPS-Summary610.doc. Accessed on: 26 Jul 2012

34. National Drug Intelligence Center U.S. Department of Justice. National Drug Threat Assessment (2007) Product No. 2006Q0317-003. Oct 2006
35. Cantrill S and the American College of Emergency Physicians Opioid Guideline Writing Panel. Clinical policy: critical issues in the prescribing of opioids for adult patients in the emergency department. Approved by the ACEP Board of Directors, June 14, 2012. http:// www.acep.org/clinicalpolicies/ and http://www.acep.org/WorkArea/ DownloadAsset.aspx?id=86527. Accessed on: 5 Aug 2012

36. National Alliance for Model State Drug Laws. http://www.namsdl.org/ documents/StrongComponentsPMPStatuteProgram6-2012.pdf. Accessed on: 26 July 2012

37. National Alliance for Model State Drug Laws. Interstate sharing of prescription monitoring program data pursuant to statute, regulation, and/or statutory interpretation. http://www.namsdl.org/ documents/InterstateSharingofPMPData07312012.pdf. Accessed on: 5 Aug 2012

38. Yeh T (2010) CRS report R40548, Legal issues relating to the disposal of dispensed controlled substances. http://www.fas.org/ sgp/crs/misc/R40548.pdf. Accessed on: 18 Aug 2012 